\title{
O Impacto do Transplante Hepático Infantil na Dinâmica Familiar
}

\author{
The Impact of Pediatric Liver Transplantation on Family Relations
}

\author{
Márcia Camaratta Anton* \& Cesar Augusto Piccinini \\ Universidade Federal do Rio Grande do Sul
}

\begin{abstract}
Resumo
O presente estudo buscou compreender o impacto do transplante hepático infantil (THI) na dinâmica familiar. Participaram da pesquisa seis mães de crianças transplantadas de fígado. O tempo pós-transplante variou entre um e seis anos. As mães foram entrevistadas a respeito do relacionamento familiar no contexto do THI. Análise de conteúdo qualitativa revelou que a relação genitores-criança doente foi permeada pelo medo da morte, levando a atitudes permissivas e superprotetoras, na tentativa de poupar o filho de mais sofrimentos, sendo que este padrão de relacionamento manteve-se presente mesmo após o transplante e a melhora do quadro de saúde dos filhos. A relação do casal tendeu a fortalecer-se e centrar-se nas preocupações a respeito da doença e do transplante, havendo mais diálogo e união. A relação com os filhos sadios passou para segundo plano, surgindo sentimentos de desamparo, ciúmes e rivalidade nas crianças. A família extensiva, por sua vez, tendeu a tornar-se mais próxima e apresentou um importante papel de apoio. Os resultados apontaram que toda a família foi afetada, havendo necessidade de reestruturação familiar, o que reforça a importância do acompanhamento psicológico precoce e sistemático às famílias, visando facilitar a adaptação à situação de doença, prevenindo o desenvolvimento de problemas emocionais.
\end{abstract}

Palavras-chave: Transplante hepático infantil; Dinâmica familiar; Psicologia.

\begin{abstract}
This study attempts to understand the impact of pediatric liver transplantation on family relations. Six mothers of two-parent families whose children had been submitted to liver transplant within the last six years participated in the study. Mothers were interviewed about family relationships in the context of pediatric liver transplantation. Qualitative content analysis of the interviews revealed that parents-child relationship was marked by fear of death, leading to permissive and overprotective attitudes in order to reduce the child's suffering. It was noted that this pattern of behavior was maintained even after transplantation and patient's recovery. Parents' relationship tended to fortify and focus on the child's transplant and illness. Parents' relationship with their healthy children was affected. These children developed feelings of abandonment, competition and rivalry. Relatives tended to become closer and played an important supportive role. The results showed that all family members were affected and needed restructuring which reinforces the importance of early and systematic psychological assistance to the families aiming at a better adaptation to the child's condition, preventing the development of emotional problems. Keywords: Pediatric liver transplant; Family relations; Psychology.
\end{abstract}

O diagnóstico de uma doença crônica em um membro da família e, em particular em uma criança, tende a afetar o funcionamento de cada um e do sistema familiar como um todo. Já a experiência de doença crônica, somada à situação de transplante, pode produzir sentimento de caos (Wise, 2002) e desorganizar o mundo do paciente e da família, que é forçada a fazer muitos ajustamentos (Engle, 2001). A rotina diária de todos muda com visitas constantes ao médico, administração de medicações, exa-

*Endereço para correspondência: Universidade Federal do Rio Grande do Sul, Instituto de Psicologia, Departamento de Psicologia do Desenvolvimento e da Personalidade, Rua Ramiro Barcelos, 2600, sala 111, Porto Alegre, RS, Brasil, CEP 90035-003. E-mails: manton@hcpa.ufrgs.bre piccinini@portoweb.com.br mes, internações hospitalares, requerendo uma demanda adicional de toda família (Falkenstein, 2004). Todos estes fatores podem acarretar prejuízos para criança e mudanças significativas na vida social desses enfermos, com repercussões emocionais para pais e mães e implicações para as relações e dinâmica familiar (Castro \& Piccinini, 2004; Masi \& Brovedani, 1999; Tarbell \& Kosmach, 1998).

A situação de transplante pode também tensionar as relações com amigos e colegas (Engle, 2001). A família tende a se isolar, tornando mais intensos os traços e tendências psicopatológicas de cada um (Kärrfelt, Berg, \& Lindblad, 2000; Wise, 2002). Além disso, os genitores, em função do papel de cuidadores, tendem a tornar-se hiper-vigilantes, o que pode aumentar o sentimento de 
vulnerabilidade dos mesmos. Como conseqüência, podem sentir-se desamparados e menos capazes de lidar com o filho enfermo (Wise, 2002).

É comum nestas situações, o relacionamento do casal ficar em segundo plano, com o surgimento de problemas maritais e fraternais (Fine et al., 2004). Os irmãos do paciente muitas vezes precisam reajustar-se e reagem com ansiedade, ressentimento e culpa (Lewis \& Wolkmar, 1993). As mães tendem a voltar toda sua atenção para a criança doente, abdicando de interesses pessoais e profissionais para cuidar do filho enfermo. Os planos familiares muitas vezes precisam ser modificados, podendo haver interrupção dos objetivos futuros. Tudo isso pode vir acompanhado por perda de rendimentos e ameaça ao bem-estar econômico (Engle, 2001), além de significante sofrimento psicológico (Kärrfelt et al., 2000).

Os genitores também podem ter a percepção acerca de seus filhos profundamente atingida, sendo que esta surge invariavelmente misturada com preocupações e ansiedades dos mesmos (Piccinini, Castro, Alvarenga, Vargas, \& Oliveira, 2003). Por exemplo, o estudo de Adebäck, Nemeth e Fischler (2003) mostrou que genitores de crianças transplantadas de fígado tendiam a ver seus filhos como extremamente mais vulneráveis que as outras crianças.

De qualquer modo, a maior parte dos pais muda suas atitudes, imperceptivelmente ou acentuadamente, quando o filho se encontra enfermo. O adoecimento, por vezes, pode ser a ocasião em que a criança consegue a atenção integral da mãe e que esta, por encontrar-se ansiosa em relação à saúde do filho, pode suspender todas as considerações a respeito de disciplina, cedendo a todos os desejos infantis (Anton, 2006; Freud, 1952; Lewis \& Wolkmar, 1993). Além disso, os membros da família, na tentativa de poupar e amenizar o sofrimento, também tendem a desenvolver atitudes permissivas e superprotetoras (Castro \& Moreno-Jiménez, 2005; Kärrfelt et al., 2000; Masi \& Brovedani, 1999; Piccinini et al., 2003; Sokal, 1995; Törnqvist, et al., 1999). Tais dificuldades de manejo, que envolvem a maneira como a disciplina é introduzida e conduzida, tendem a ser permeadas pelo temor de que imposição mais severa de limites possa afetar o estado de saúde da criança, trazendo efeitos inclusive letais (Masi \& Brovedani, 1999; Piccinini et al., 2003).

Estudo desenvolvido por Piccinini et al. (2003) indicou que as mães de crianças com doença crônica tendiam a usar menos práticas coercitivas do que as mães de crianças sem problemas de saúde. O uso menos freqüente dessas práticas não implicava, por outro lado, na maior utilização de práticas indutivas, sendo que a média geral de práticas utilizadas pelas mães de crianças doentes mostrou-se significativamente inferior à média geral do grupo sem doença, o que pode indicar a grande dificuldade encontrada por estas mães em educar seus filhos, provavelmente associada ao medo da morte, ao receio de causar mais sofrimento e ao desejo de aproveitar sua convivência ao máximo, sem ter de submeter à criança a outras frustrações e momentos estressantes, como os implicados na educação dos filhos.

Assim, a presença de doença crônica e a necessidade de transplante constituem-se em organizadores de respostas parentais às crianças, com consequiências para as interações pais-criança (Castro \& Moreno-Jiménez, 2005; Piccinini et al., 2003). Neste sentido, Ferreira, Vieira e Silveira (2000) afirmaram ser essencial encorajar a criança e a família a retornarem à vida normal, sendo que a família deveria, aos poucos, parar de tratar o filho como uma criança doente. Lewis e Wolkmar (1993) corroboram esta idéia ao postular que os genitores devem reavaliar sua percepção e respostas às necessidades do filho. Soma-se a isto o fato de que as crianças crescem e vão apresentando novas aquisições afetivas, cognitivas, comportamentais e sociais que precisam receber atenção dos pais para que possam se desenvolver adequadamente. Neste contexto, uma ênfase demasiada na enfermidade, não contribui para as novas aquisições infantis, que necessitam a atenção e incentivo da família.

No caso de doença crônica e transplante, as famílias percebem e reagem à enfermidade, seus efeitos e implicações de várias maneiras (Falkenstein, 2004). Algumas conseguem integrar a condição da doença como parte da rotina diária. Para outras, isto é algo muito mais difícil. Portanto, cada família tende a desenvolver a sua maneira de definir os papéis e responsabilidades de cada membro no cuidado para com a criança enferma, sendo que as variações podem ser igualmente efetivas. Nas situações envolvendo transplante de órgãos infantis, Tarbell e Kosmach (1998) identificaram o ambiente familiar como um preditor importante associado com a saúde mental dos pais, sendo que conflitos familiares elevados foram também associados com um maior sofrimento emocional dos pais. Assim, ficar atendo à própria família, além da criança, é importante quando se avaliam os resultados psicossociais do transplante infantil.

A comunicação sobre a doença é outro importante fator que pode afetar o resultado do transplante (Falkenstein, 2004). Por exemplo, alguns estudos mostraram que o tema do transplante estava freqüentemente ausente da comunicação entre os pais e a criança (Gritti et al., 2001; Kärrfelt, Lindblad, Crafoord, \& Berg, 2003). Isto porque os genitores se mostraram muito sensíveis a conversarem a respeito do transplante e principalmente sobre a morte do doador, por considerarem temas mobilizantes e difíceis de serem abordados. Além disso, alguns pais acreditavam não ser possível para uma criança pequena entender os fatos envolvendo a doação e o transplante (Kärrfelt et al., 2000). Para alguns autores, a ausência de comunicação entre pais e filhos sobre o assunto - seja por razões culturais ou psicológicas - pode dificultar a elaboração psíquica da experiência de doença crônica e transplante, 
que tende a se tornar um processo silencioso e solitário (Anton, 2006; Gritti et al., 2001). Os achados de Kärrfelt et al. (2003) sugeriram que, quando o transplante é um segredo na família, este pode se tornar uma experiência obscura e traumática para a criança.

Apesar de todos os problemas e implicações negativas envolvidas numa situação de transplante, alguns aspectos positivos para dinâmica familiar têm sido apontados na literatura (Kärrfelt et al., 2000; Sokal, 1995), sem falar, obviamente, na melhora do quadro clínico da criança. Sokal (1995) destaca, por exemplo, que o ressentimento dos irmãos tende a diminuir - embora não desapareça quando a vida da família torna-se menos desestruturada após o transplante. Além disto, as crianças e famílias geralmente retornam a uma vida mais normal e experienciam marcada melhora no estilo de vida.

Cabe salientar que o transplante caracteriza-se como uma alternativa de tratamento para várias doenças crônicas, sem a qual a sobrevida da criança não seria possível. No entanto, as evidencias sugerem que a dinâmica familiar pode ser afetada em situação de transplante. Assim sendo, o presente estudo buscou investigar o impacto da doença crônica e do transplante hepático infantil na dinâmica familiar ${ }^{1}$.
A expectativa inicial era de que a relação genitorescriança fosse permeada pelo medo da morte, superproteção e dificuldade no manejo e imposição de limites. Esperava-se ainda que esta situação tivesse um forte impacto nas relações familiares, influenciando cada membro e a família como um todo, levando a necessidade de reestruturação das famílias.

\section{Método}

\section{Participantes}

Participaram deste estudo seis mães de crianças transplantadas de fígado, que tinham idades entre quatro e oito anos na época da coleta de dados, sendo que o tempo pós-transplante variou entre um e seis anos ${ }^{2}$. Foi utilizado como critério de exclusão: transplante de urgência, doação intervivos, re-transplante de fígado, terminalidade, comorbidade orgânica ou mental ${ }^{3}$. O nível sócioeconômico variou de baixo a médio, com base na escolaridade e profissão dos genitores. A Tabela 1 apresenta as características sócio-demográficas das mães e dos pais. A Tabela 2 apresenta as características sócio-demográficas e da doença de base das crianças.

Tabela 1

Características Sócio-Demograficas das Mães e dos Pais

\begin{tabular}{lcccccc}
\hline Mãe $/$ Pai Idade & Escolaridade & Profissão & Trabalha & Filhos & Religião \\
\hline M1 & 36 & $5^{\text {a }}$ série & Agricultora & Não & 1 & Católica \\
P1 & 39 & $5^{\text {a }}$ série & Agricultor & Sim & 1 & Católica \\
M2 & 30 & $5^{\text {a }}$ série & Calçado & Não & 2 & Evangélica \\
P2 & 34 & $5^{\text {a }}$ série & Calçado & Sim & 3 & Evangélico \\
M3 & 26 & $2^{\text {o }}$ grau & Confeç̧ão & Sim & 1 & Católica \\
P3 & 28 & $2^{\text {o }}$ grau & Motorista & Sim & 1 & Católico \\
M4 & 35 & $2^{\text {o }}$ grau & Autônoma & Sim & 3 & Católica \\
P4 & 37 & $2^{\text {o }}$ grau & Autônomo & Sim & 3 & Católico \\
M5 & 41 & $2^{\text {o grau }}$ & Do lar & Não & 3 & Evangélica \\
P5 & 48 & $2^{\text {o }}$ grau & Autônomo & Sim & 3 & Católico \\
M6 & 49 & $5^{\text {a }}$ série & Doméstica & Sim & 3 & Católica \\
P6 & 43 & $2^{\text {o grau }}$ & Mecânico & Sim & 3 & Católico \\
\end{tabular}

${ }^{1}$ Derivaram deste mesmo projeto de pesquisa outros três artigos intitulados Desenvolvimento emocional em crianças submetidas a transplante hepático infantil (Anton \& Piccinini, 2010), A experiência da maternidade no contexto de transplante hepático infantil (Anton \& Piccinini, 2010) e Aspectos psicossociais associados a diferentes fases do processo de transplante hepático pediátrico (in press). Estes artigos examinaram, os aspectos emocionais das diferentes fases do processo de transplante, a experiência da maternidade e o desenvolvimento infantil no contexto de doença crônica e do transplante.

\footnotetext{
${ }^{2}$ As crianças também foram incluídas no estudo, no entanto estes dados não serão utilizados no presente artigo. ${ }^{3}$ Com base nestes critérios dez díades foram selecionadas dentre os 100 pacientes que haviam feito transplante no Hospital de Clínicas de Porto Alegre, desde o início da realização deste procedimento, em 1996. Todas as mães de crianças que se enquadravam nos critérios de inclusão do presente estudo foram contatadas e convidadas a participar, juntamente com seus filhos. Contudo, em virtude de morarem em cidades distantes e da dificuldade em comparecerem para entrevistas no período previsto para a coleta de dados, quatro díades não puderam participar.
} 
Tabela 2

Características Sócio-Demograficas e da Doença das Crianças

\begin{tabular}{|c|c|c|c|c|c|c|c|c|}
\hline & Idade & Sexo & Escolaridade & Diagnóstico & $\begin{array}{l}\text { Idade no } \\
\text { diagnóstico }\end{array}$ & $\begin{array}{l}\text { Idade no } \\
\text { transplante }\end{array}$ & $\begin{array}{c}\text { Tempo } \\
\text { pós-transp. }\end{array}$ & $\begin{array}{l}\text { Internações } \\
\text { pós-transpl. }\end{array}$ \\
\hline $\mathrm{C} 1$ & $7^{\mathrm{a}} 5 \mathrm{~m}$ & M & $1^{\mathrm{a}}$ série & HepatiteAuto-imune & $5 \mathrm{a}$ & $5 \mathrm{a} 3 \mathrm{~m}$ & $2 \mathrm{a}$ & 3 \\
\hline $\mathrm{C} 2$ & $4^{\mathrm{a}} 8 \mathrm{~m}$ & $\mathrm{~F}$ & - & Atresia Vias Biliares & $4 \mathrm{~m}$ & $2 \mathrm{a} 8 \mathrm{~m}$ & $2 \mathrm{a}$ & 0 \\
\hline $\mathrm{C} 3$ & $8^{\mathrm{a}} 4 \mathrm{~m}$ & $\mathrm{~F}$ & $2^{\mathrm{a}}$ série & Cirrose & 1a $8 \mathrm{~m}$ & $7 \mathrm{a} 4 \mathrm{~m}$ & $1 \mathrm{a}$ & 5 \\
\hline $\mathrm{C} 4$ & $66^{\mathrm{a}} 5 \mathrm{~m}$ & $\mathrm{~F}$ & $1^{\mathrm{a}}$ série & Atresia Vias Biliares & $1 \mathrm{~m}$ & $8 \mathrm{~m}$ & $6 a$ & 1 \\
\hline $\mathrm{C} 5$ & $7^{\mathrm{a}} 8 \mathrm{~m}$ & $\mathrm{~F}$ & $2^{\mathrm{a}}$ série & Atresia Vias Biliares & $1 \mathrm{~m}$ & 1a $1 \mathrm{~m}$ & $6 a$ & 4 \\
\hline $\mathrm{C} 6$ & $7^{\mathrm{a}} 7 \mathrm{~m}$ & M & $2^{\mathrm{a}}$ série & Atresia Vias Biliares & $2 \mathrm{~m}$ & 2a $1 \mathrm{~m}$ & $5 \mathrm{a}$ & 1 \\
\hline
\end{tabular}

\section{Delineamento, Procedimentos e Instrumento}

Foi utilizado um delineamento de estudo de caso coletivo (Stake, 1994), buscando investigar o impacto da doença crônica e do transplante hepático infantil na dinâmica familiar, em famílias com diferentes períodos de pós-transplante. As famílias selecionadas com base nos critérios descritos acima, foram convidadas a participar do estudo quando compareceram a consultas médicas ou por telefone. Todas as mães que aceitaram participar preencheram inicialmente a Ficha de Contato Inicial e a assinaram o Termo de Consentimento Livre Esclarecido ${ }^{4}$. Horários individuais foram agendados para a realização da Entrevista sobre a experiência da maternidade e o relacionamento familiar no contexto do transplante hepático infantil (Anton \& Piccinini, 2006b) $)^{5}$, que abordava diversos temas como: auto-percepção materna, sentimentos relacionados ao ser mãe neste contexto; impressões da mãe sobre o papel do pai e os sentimentos do mesmo em relação à paternidade; influência da doença e do transplante nas relações familiares - genitores-criança enferma, entre o casal, com os irmãos e com demais familiares. Esta é uma entrevista estruturada, elaborada para fins deste estudo, que foi realizada de modo semi-dirigido. As perguntas eram abertas e permitiam aprofundamento dos conteúdos no decorrer da entrevista. Todas as entrevistas foram realizadas individualmente, pela primeira autora deste artigo, em sala de atendimento psicológico do Serviço de Psicologia do Hospital de Clínicas de Porto Alegre, com a duração aproximada de duas horas, tendo sido gravadas e posteriormente transcritas.

\section{Resultados e Discussão}

Análise de conteúdo qualitativa (Laville \& Dione, 1999) foi utilizada para se investigar o impacto da doença crônica e do transplante hepático infantil na dinâmica familiar. Com base na leitura exaustiva das entrevistas e na experiência da primeira autora deste estu$\mathrm{do}^{6}$, foram inicialmente criadas quatro categorias temáticas que têm se mostrado importantes no contexto da doença crônica e THI: relação genitores-criança, relação do casal, relação com os irmãos, relação com a família extensiva. Durante as análises buscou-se investigar tanto as particularidades como as semelhanças entre os casos, com destaque para o tempo pós-transplante, que variou entre um e seis anos. Apresenta-se, a seguir, cada uma das categorias, exemplificando-se com os relatos das próprias mães ${ }^{7}$. Após a apresentação dos resultados de cada categoria, discute-se os achados à luz da literatura.

\section{Relações Genitores-Criança}

De acordo com os relatos maternos, pôde-se perceber que a relação genitores-criança foi afetada desde o início da doença, de diferentes formas. Uma das mães relatou que, desde quando souberam do diagnóstico da doença e da possibilidade de transplante, ela e o marido esforçaram-se para tratar a filha sem distinção, pois consideraram que lidar de maneira diferenciada poderia tornála mais frágil. Assim, preocuparam-se em criar uma criança forte e capaz de enfrentar as adversidades impostas pela doença: "A gente sempre tentou manter igual desde pequena pra não... A gente ficava com medo de criar uma criança muito frágil. Ela tem que saber se

${ }^{4} \mathrm{O}$ projeto de pesquisa foi avaliado e aprovado pelo Comitê de Ética em Pesquisa do Hospital de Clínicas de Porto Alegre. (Projeto n ${ }^{\circ}$ 06-054)

${ }^{5}$ Outros instrumentos foram utilizados num segundo encontro, a saber: Entrevista sobre a história da doença e do transplante hepático infantil (Anton \& Piccinini, 2006a); Entrevista sobre o desenvolvimento emocional da criança no contexto do transplante hepático infantil (Anton \& Piccinini, 2006c); e o Teste das Fábulas aplicado às crianças. Os dados derivados destes instrumentos não serão utilizados no presente artigo. 
virar um dia também" $(M 3)^{8}$. Neste sentido, estes pais se deram conta de que talvez o que fosse o melhor para a filha não necessariamente seria o melhor ou o mais fácil para eles. Assim, deram suporte para ela se desenvolver bem, mesmo que isto exigisse uma conscientização e um esforço especial da parte deles: "A gente sempre fez o que a gente achava melhor pra ela, não o que era melhor ou mais fácil pra nós" (M3).

Em relação ao manejo com as crianças, algumas mães (M1, M3, M4) referiram ser firmes e tratar como tratariam qualquer outro filho: "Sempre tratei normal, mesmo com tudo que aconteceu. Se tinha que pôr limites eu colocava. Se tinha que punir a gente punia" (M3). Outras (M2, M5, M6), mostraram que às vezes tinham dificuldades em contrariar os filhos e acabavam tratando-os de forma mais condescendente: "O castigo nunca dura. Dura só até ela dizer: 'eu posso ir?' 'Pode'”, (M5).

De modo semelhante, alguns dos pais, segundo as mães (M4, M6), tinham dificuldade de ser firmes com os filhos: "Ela pega muito o pai dela no choro" (M4); "Com o pai ele faz gato e sapato. Ninguém pode xingar o $C^{9 "}$ (M6). Outras mães (M2, M3, M5) referiram que os maridos eram vistos como as figuras de autoridade, com relação aos quais os filhos tinham mais respeito, mesmo quando também eram afetivos de uma forma geral: "Ele tem mais paciência que eu. Mas fala uma vez só e fala grosso, ela já vai pro canto dela. Ela respeita muito ele" (M3).

A falta de concordância entre a mãe e o pai em relação ao manejo com o filho também foi enfatizada por algumas mães (M2, M4, M5, M6): "Um tira a autoridade do outro. Assim a guria vai ficar sem vergonha. Vai chegar num ponto que não vai obedecer nem a mim nem a ele" (M4). Outras mães (M1, M3), por sua vez, destacaram que o casal buscava estar unido e ter um manejo em comum.

Durante as entrevistas ficou claro que os genitores, segundo as mães, procuravam utilizar mais as práticas educativas indutivas do que coercitivas: "Ela teima um pouco. Tem que levar na conversa” (M2). Neste sentido, as mães também enfatizaram o quanto elas procuravam explicar para os filhos o porquê das imposições:" $E u$ tenho que explicar, conversar, pra daí ela entender $e$ pronto, tá tudo bem" (M3). A utilização da barganha como forma de manejo foi bastante comum: "Ela aceita substituições" (M5); "Eu faço chantagem com ele. Se não tomar banho não vai ver TV" (M6). Já a utilização de punição física foi citada por apenas uma mãe (M6), que mostrou sentir-se mal quando batia no filho.

Em algumas situações, a dificuldade de colocar limite ficou particularmente evidente, aparecendo uma falta de disciplina e de controle sobre a criança:

A gente mimou muito de lá para cá e agora tá ficando grande. Ele me chama de louca. Ele bate boca comigo.

${ }^{8}$ Os relatos maternos foram identificados por ' $M$ ' seguido dos números de 1 à 6 , conforme apresentado na Tabela 1 .

${ }^{9}$ Quando as mães referiram-se aos filhos pelos nomes, estes foram substituídos pela letra "C".
É teimoso. Ele olha bem sério pra mim e pro pai dele e ele fala o que ele fez. Ai ele diz assim 'eu não tô nem ai'. (M6).

Neste aspecto, algumas mães (M2, M4, M5, M6) deram-se conta de que elas e os maridos acabaram superprotegendo os filhos, em virtude da história de doença e transplante:

"Ela teve mais atenção, carinho redobrado. Tudo o que ela via na frente ela queria, tudo que ela pedia o pai dava" (M4); "Ele sabe que é o filhinho do papai e da mamãe. Ele é muito mimadinho. Mas por tudo o que ele passou também, né? Um transplante de fígado!" (M6).

Em um dos casos, a mãe mostrou o quanto ela e seu marido ficavam assustados e com medo de que qualquer contrariedade prejudicasse o estado de saúde do filho: "A gente não deixa ele ficar nervoso, até tem medo, porque se deixar nervoso dá rejeição [do órgão transplantado]. Então a gente não xinga ele, não briga com ele, pra ele não ficar tenso nem nervoso" (M6).

Em algumas situações, a superproteção levava a um cerceamento por parte das mães em relação às crianças: "Eu sempre ficava em cima dele, afogava ele com os cuidados. Ele dizia, 'ai mãe, me larga um pouco'. Às vezes eu paro pra pensar: 'será que não tô exagerando?'” (M6). Apesar de algumas mães (M2, M4, M6) em muitos momentos associarem a superproteção à situação de doença, em outros, procuraram justificá-la de outras formas, parecendo, por vezes, tentar negar a influência da doença na vida deles: "Era mimada por ser a única menina" (M4).

No que diz respeito à relação do pai com a criança, muitas mães (M1, M2, M3, M6) salientaram o aspecto mais tranqüilo da relação. Referiram que os pais pareciam menos temerosos, realizando, de forma geral, brincadeiras mais descontraídas e ativas: "Brincam de tudo. Ele pega, joga ela pra cima, conta história. Faz ela rir um monte" (M2). Uma das mães descreveu o marido como sendo tranqüilo em relação às brincadeiras, mas considerou-o exageradamente preocupado com os cuidados de saúde do menino: "Ele exagera um pouquinho mais do que eu. Qualquer resfriado que o C pega, já é um carnaval dentro de casa" (M6).

A comunicação com a criança em relação a aspectos relacionados à doença e ao transplante também foi mencionada nas entrevistas. Em muitas situações as mães relataram que o casal teve dúvidas se o melhor para o filho seria falar sobre o assunto ou permanecer em silêncio. Alguns casais, de acordo com a perspectiva das mães (M1, M2, M3, M4), consideraram que evitar falar coisas negativas enquanto estivessem juntos seria uma forma de poupar a criança de mais sofrimento. Nestes casos, o diálogo sobre os aspectos difíceis da doença e do tratamento foi reservado só para os adultos: pais, familiares e equipe do hospital. Isto ocorria muitas vezes como forma de tentar poupar a criança de mais sofrimento: "A gente conversava, tinha medo, aquela angústia. Mas com ela a gente sempre passava o melhor, sempre o melhor" (M3). 
Outras mães (M3, M5) relataram que o casal procurava explicar, dentro do que julgava adequado para as capacidades de entendimento da criança, tudo que ocorria: "A gente nunca deixou de contar que era preciso aquilo ali, que ele tinha um fígado doente, que ele ia ter que colocar um figado que não fosse doente" (M3). Outras (M1, M2, M4), omitiram alguns conteúdos, por considerarem pesados ou de difícil compreensão: “ $E u$ expliquei direitinho, só não falei da menina que morreu para ela não ficar, sabe? Conforme o assunto eu não conto detalhes ainda pra ela. Um dia, com o tempo, ela amadurece" (M4). No entanto, o assunto do doador pareceu ser um tabu para quase todas as famílias, já que apenas uma das mães conseguia conversar com sua filha sobre isso: "Eu dizia pra ela: 'não filha, às vezes algumas pessoas têm que morrer para salvar outras"” (M3).

Uma das mães no pós-transplante passou a questionar o benefício de falar sobre a doença e o transplante com o filho, pois temia ficar remoendo um assunto difícil: " $E u$ acho que não é bom tá revivendo. De repente pra ele é, só que eu não gosto de ver com ele o passado" (M1).

De acordo com os relatos maternos descritos acima, pode-se perceber que, na relação genitores-criança, a tentativa de poupar o filho de mais sofrimentos esteve muito presente, independentemente do tempo pós-transplante e do número de intercorrências e internações sofridas. Durante o período pré e pós-transplante imediato os pais e mães centraram-se na doença e na tentativa de proteger os filhos das más-notícias e prepará-los para os procedimentos, internações e outros aspectos sofridos impostos pela doença e o tratamento. No entanto, mesmo após o período agudo de doença, parece que este padrão de comportamento continuou presente, talvez de forma menos consciente. Isto ficou evidenciado na dificuldade de impor limites, na superproteção e nos privilégios que continuaram sendo dados para a criança transplantada, independentemente do tempo transcorrido desde o transplante.

\section{Relação do Casal}

No que diz respeito à relação do casal propriamente dita, muitas mães (M1, M2, M3, M6) referiram a intensificação do vínculo para enfrentar a doença e o transplante: "Eu acho que com a doença a gente ficou mais unido" (M1). As mães consideraram que a maior proximidade fez com que o diálogo entre o casal fosse mais freqüente: "A gente teve que ser forte e isso aí contribuiu. Serviu pra gente ficar mais perto, para conversar mais" (M2).

Três mães (M1, M3, M6) enfatizaram a participação intensa do marido e a importância deste suporte para enfrentarem as exigências que a doença impunha: "Nós corremos juntinhos. Ele nunca me deixou ficar estressada" (M6); "Ele foi o principal alicerce. Sem ele eu não conseguiria ter feito nada do que eu fiz. Acho que não teria conseguido" (M3). A participação desses com- panheiros não se limitou ao apoio emocional às mães, já que participavam dos cuidados com a criança, no hospital e em casa. Já outras mães (M2, M4, M5) não contaram tão intensamente com o apoio direto dos companheiros no que dizia respeito aos cuidados com os filhos. No entanto, no que se referiu ao respaldo financeiro e ao auxílio aos filhos sadios, estes foram assegurados pelos mesmos: "Ele ia às consultas comigo. Financeiramente assumiu todas as despesas. Ele deu mais apoio para os outros filhos fora do hospital" (M5).

Uma das mães comentou que, de certa forma, a situação de doença e necessidade de transplante surgiu como um desafio na vida do casal, já que impunha uma série de restrições difíceis de manejar, segundo sua perspectiva, principalmente quando se está iniciando uma vida conjugal:

Era complicado a vida da gente. Aí tu começa a brigar com o teu marido, começa a rolar confusão dentro de casa, aquela brigaceira, sabe? Mas a gente colocou a cabeça no lugar e pensou só naquilo, a gente queria ter ela bem. (M3).

Esta mãe ressaltou que, se não houvesse união entre o casal, e se tivesse havido acusações e não companheirismo, teriam se separado.

Outra mãe lembrou que, na época da internação, a vida do casal ficou voltada para o filho, pois havia algo maior envolvido, que era a luta contra a doença. No entanto, quando retornaram para casa, considerou que a vida voltou ao normal: "No tempo que a gente ficou no hospital [a doença interferiu], mas do contrário a gente foi pra casa e a vida continuou normal" (M1).

Em alguns casos (M2, M3), durante as internações, os casais tiveram que passar mais tempo sem se ver e se falando apenas por telefone, especialmente no caso de famílias que residiam em cidades distantes. Uma das mães relatou o quão difícil considerou este afastamento do marido: "É difícil ficar longe. A gente sofre muito. Mas a gente passava força um pro outro, união... A gente se falava no telefone, todo o dia" (M3).

O aumento no tempo disponível para o casal depois do transplante também foi referido pelas mães: "Mudou que agora temos um tempo pra a gente, que a gente não tava tendo. E isso é bem importante. Poder sair, se divertir, fazer alguma coisa diferente" (M3). Por outro lado, a dificuldade de se separar e de impôr limites para a criança, abordada anteriormente, também foi mencionada por algumas mães (M2, M4, M6) por terem influenciado a vida de alguns casais: "Não temos um tempinho pra gente porque o C 'tchum' na nossa cama" (M6).

Uma das participantes relatou que, a partir do adoecimento da filha, sua relação conjugal passou para segundo plano: "Naquela época ele passou a ser o secundário na minha vida, porque a minha energia era canalizada toda nela” (M5). Esta mãe comparou ainda a relação deles antes e depois do nascimento da filha doente:

Eu não vivia sem ele, não respirava sem ele. Quando a $\mathrm{C}$ nasceu foi que eu me dei conta que eu vivia sem 
ele, que ele era uma parte dispensável na minha vida: eu não vivia sem a minha filha. (M5).

Esta mãe considerou que somente a partir do nascimento e adoecimento da filha pôde conhecer seu companheiro de verdade:

Eu pude analisar ele mais como ser humano, como homem, sem ser o homem que eu amava. Aprendi a conhecer ele, a aceitar, a conhecer os defeitos e também ver o lado positivo, porque ninguém é só defeito, ninguém é só qualidade. (M5).

Depois disso, esta mãe passou a considerar que a relação do casal ficou muito mais madura e real: "Uma relação melhor, sem sofrimento, uma relação adulta: sem pressão, sem medo de perda, sem medo de nada. Aquela sensação de "não vivo sem ele, não vivo longe dele', acabou” (M5).

Os relatos acima mostram que, com relação ao casal, o aspecto mais salientado pela maioria das mães foi a ocorrência de uma maior proximidade e diálogo, com exceção de uma delas que acabou se afastando do marido e investindo acentuadamente na filha enferma. Além disso, o desafio que a doença e o transplante representaram na vida do casal também foi salientado, já que trouxe uma série de dificuldades que envolveram restrições financeiras, afastamento físico do casal, falta de tempo e energia para investir nessa relação, conflitos familiares e o próprio estresse causado pela doença. Neste sentido, a importância da união do casal como fator de manutenção da relação e da vida familiar ficou aparente. Além disso, a melhora do quadro clínico pós-transplante surgiu como fator que facilitou a retomada da vida de casal em alguns casos. Já em outros, a permissividade com o filho transplantado e o excesso de preocupações com o mesmo parece ter interferido muito na vida conjugal. Estes aspectos apareceram mais associados à postura dos pais diante do filho, da doença e do transplante, do que em relação às intercorrências ou ao tempo pós-transplante.

\section{Relação com os Irmãos}

No que se refere aos irmãos pôde-se constatar pelos relatos de algumas mães (M2, M4, M5, M6) que estes acabaram ficando em segundo plano, já que as crianças enfermas exigiam muita atenção. Em várias ocasiões, os irmãos ficaram aos cuidados dos avós ou tios, já que a mãe necessitava permanecer no hospital com o filho enfermo e o pai tinha que trabalhar: "Seguido a minha irmã levava o [filho sadio], ficava durante uma semana lá, quando eu achava que a $C$ precisava de mais atenção. Ele já tava acostumado” (M2). Nestas circunstâncias, as mães pareciam considerar positivas para os filhos sadios estas saídas de casa, já que estavam sendo bem cuidados e recebiam atenção dos parentes. Com isto, conseguiam se tranqüilizar para cuidar do filho enfermo, em casa ou no hospital: "Meu guri [sadio] tava bem cuidado, não tinha com o que eu me preocupar” (M2).

Além disso, as mães relataram que os irmãos também estavam cientes do problema de saúde do irmão enfer- mo: "Sabiam, tinham idéia que a irmã não iria sobreviver sem o transplante e também tinham idéia que ela podia morrer no transplante. Eles sabiam exatamente o que estava se passando, o que acontecia” (M5). Algumas mães (M5, M6) explicaram mais detalhadamente sobre a doença e o transplante, falando do risco de morte, enquanto outras (M2, M4) apenas disseram que precisariam ficar no hospital. Em algumas situações, a comunicação sobre a doença ficou delegada a outros familiares. Uma das mães, na verdade, apenas supunha que os filhos tinham sido comunicados, tamanho o envolvimento com a situação de doença: "De certo lá conversavam, explicavam isso ai pra eles. Eu tive pouca conversa com eles. Vim pro hospital com a cabeça assim. Mas eu deixei essa parte pra avó, pro [marido]” (M4).

Foi possível constatar também que os filhos sadios ficaram muito envolvidos com a doença dos irmãos e com o estado de saúde dos mesmos. Em muitas situações, inclusive, acabavam assumindo alguns cuidados: "Ele cuida dela como se ela fosse um bibelô. Se preocupa se ela tá com frio, se tomou o remédio" (M5). Uma das mães comentou que delegou ao filho sadio, de cinco anos na época, a tarefa de segurar a irmã para que ela pudesse passar a sonda na filha enferma, sendo que este era um procedimento sofrido para todos eles: "Tinha que vir o [irmão] me ajudar a segurar ela. Eu botava na cama, ele me ajudava, segurava os braços, as pernas, porque sozinha eu não conseguia. Não é fácil, nossa!” (M2).

Um dos irmãos, com oito anos de idade, chegou a se oferecer como doador, tamanha a preocupação com a irmã enferma e o desejo de retomar a vida normal. Este fato causou grande impacto na mãe: "Um dia meu guri: 'mãe posso ser doador? Porque se todas as pessoas fossem doadoras a minha irmã já teria transplantado e nós estaríamos vivendo uma vida normal'” (M5).

Além do grande envolvimento emocional dos filhos sadios com a doença dos irmãos, estes ainda tiveram que lidar com o maior afastamento dos pais em virtude da situação vivida, como exposto anteriormente. Uma das mães mostrou claramente a consciência do sentimento de perda que isto ocasionou nos filhos sadios: "Eles tavam na expectativa de receber uma irmã e dali a pouco perderam a irmã e perderam a mãe. Perderam aquela mãe que ficava sempre junto e a irmã que esperaram nove meses para nascer" (M5). Em muitas situações as mães (M4, M5, M6) relataram a carência e o desejo de proximidade dos filhos sadios em relação à mãe: "Eles queriam ficar junto. Diziam: 'ai mãe vem pra cá dormir comigo, porque a senhora fica tanto lá'” (M6). Uma das mães salientou as dificuldades de aprendizagem apresentadas por um dos filhos sadios devido ao fato da atenção ter ficado voltada para a filha doente:

$\mathrm{O}$ do meio repetiu o ano. Eu me lembro que em agosto ele me pediu um caderno, quando foi em dezembro eu 'meu filho, cadê tua matéria?'. 'Mãe, eu te pedi um caderno e tu nunca comprou para mim'. Eles foram esquecidos completamente, né? (M5). 
Apesar dessas ocorrências, todas as mães pareciam não querer reconhecer que os filhos sadios poderiam estar sofrendo intensamente com o afastamento. Isto pode estar associada ao fato de que ver o sofrimento dos filhos sadios aumentava ainda mais o seu próprio sofrimento e impotência, já que parecia não haver alternativa para lidar com a situação: "Ela necessitava mais do que eles. Não tinha opção. Era uma necessidade. Eu precisava ser mãe só dela. Ela precisava do meu amor, do meu carinho, do meu cuidado pra que hoje pudesse estar como está" (M5). Orgulho pelo fato dos filhos aceitarem o afastamento dos pais sem reclamarem também ficou evidenciado em todas as mães: "Foram uns guris calmos, não deram trabalho nenhum. Eles entendiam” (M4).

Por outro lado, em muitos dos casos (M2, M5, M6) sentimentos de inveja e rivalidade foram verificados, assim como rancor pelo fato do irmão enfermo ter sido protegido e privilegiado. Em algumas circunstâncias, os filhos sadios acabavam, inclusive, sendo relegados devido à superproteção dispensada ao filho enfermo:

“Meu outro diz: 'Tudo pro C'. E eu digo 'não é pro $C$, tem que ver o que ele passou. Um transplante de figado'. Eles brigam até por causa de salgadinho [porque o marido compra só para o filho transplantado].” (M6).

Uma das mães, por outro lado, questionou a respeito da repercussão que o seu intenso afastamento dos filhos sadios e a total dedicação à filha enferma podem ter causado na vida dos primeiros:

Eu esqueci que tinha dois filhos. Eu não sei como isso interfere na vida deles. A princípio teria uma pouca atenção. Eles ficaram órfãos de mãe, porque nesse período que ela precisou de mim eu realmente deixei de ser mãe deles e passei a ser mãe só dela. Agora eu sou mãe dos três, mas quando ela nasceu, eu fui mãe só dela. (M5).

Apesar desta mãe questionar-se sobre as consequiências dessa falta na vida dos filhos mais velhos e não encontrar os sinais da mesma, ao descrever um destes filhos, destacou a fragilidade e a excessiva dedicação dele à irmã:

Às vezes ele sai e quando chega a hora do remédio me liga: 'mãe, tu já deu o remédio?' É muito carinhoso. Ele é um bebê, ele já tem 16 anos e quando eu vejo ele tá se aninhando de baixo das minhas cobertas 'ah mãe, me dá um beijinho, deixa eu deitar aqui contigo'. (M5).

Esta fragilidade e dedicação talvez possam ser entendidas como uma conseqüência da vivência anterior, que, pelo descrito pela mãe, envolveu sentimentos de abandono em virtude da centralização da atenção na irmã enferma.

Apesar das dificuldades destacadas acima, todas as mães afirmaram que os irmãos se relacionavam bem com o irmão enfermo e que brincavam bastante juntos. No entanto, nas brincadeiras também o cuidado em função da doença, estava sempre presente: "Quando eles começam a brincar aquelas brincadeiras meio... se empurram, né? Aí eu já tenho que... Tem que tá sempre falando [para não machucar o irmão enfermo ou bater na barriga]” (M2).
Os relatos acima mostram que os irmãos das crianças transplantadas, além de terem sofrido o impacto do estresse da doença, tiveram que lidar com o intenso afastamento dos pais e maior dedicação ao irmão enfermo. De uma forma geral, pelo menos durante o período agudo da doença, estas crianças ficaram em segundo plano e foram cuidados por parentes. $\mathrm{O}$ impacto negativo que a situação de doença e afastamento dos pais pode ter causado nessas crianças foi pouco mencionado pelas mães. No entanto, em suas verbalizações, aspectos relacionados à inveja, rivalidade e mágoa por terem se sentido relegados foram evidenciados. Esses aspectos mostram o impacto que a doença e o transplante podem ter também na vida dos irmãos, não apenas no período agudo da doença, mas mesmo com o passar dos anos.

\section{Relação com a Família Extensiva}

No que diz respeito ao impacto da doença e do transplante na relação da família com os demais parentes, quase todas as mães (M1, M2, M3, M4, M6) afirmaram não ter percebido mudanças expressivas. No entanto, ao mesmo tempo, sentiram que a família tornou-se mais próxima: "Mas alterar, alterar assim a relação da gente, não. Pelo contrário, teve mais união. Claro, que de repente eles ficaram com um pouco mais afeto pela gente, que a gente passou por isto" (M4). Chama atenção que essas mães se deram conta de alterações, mas tenderam a dizer que nada mudou, embora tenha havido inclusive mudanças positivas.

A importância do apoio da família extensiva em um período tão difícil da vida, que dizia respeito à doença, risco de morte e necessidade de reestruturação familiar, foi destacada por todas as mães:

Eu acho que o mais importante é ter união da família.

Porque sem união tu não vai a lugar nenhum, tu não vai enfrentar tudo o que tem que enfrentar. Se tu não tiver um alicerce do teu lado tu não vai conseguir, porque a barra é pesada. (M3).

A participação da família extensiva envolveu o auxílio no cuidado da criança enferma e/ou dos filhos sadios que ficaram em casa, apoio emocional, mesmo que à distância, ajuda financeira, no trabalho e alojamento próximo ao hospital, no caso das famílias residentes em outras cidades. Os avós, principalmente, foram citados por todas as mães como figuras de apoio, com quem podiam dividir tarefas e deixar a criança aos cuidados, quando necessário.

Além desses aspectos, algumas mães (M1, M3, M5, M6) abordaram o excesso de cuidados e superproteção da família com o filho transplantado, mostrando que isto estava associado às experiências sofridas que passaram e que queriam evitar repetir de qualquer forma: "A gente cuida por demais. Porque cada experiência que a gente já passou... A gente queria que ele ficasse sempre bem" (M6). Duas mães (M1, M3) referiram que elas e os maridos tinham uma postura mais firme também com os avós, procurando fazer com que todos seguissem as mesmas 
orientações que acreditavam ser prioridades na educação de seus filhos, apesar da doença: "Quando a gente achava que tinha alguma coisa errada [no manejo dos avós] a gente 'não, não pode fazer isso'” (M3).

Apenas uma das mães afirmou ter tido dificuldades com a família extensiva, principalmente pela resistência dos parentes em aceitar a doença e a indicação de transplante. Desta forma, o período pré-transplante ocasionou conflitos familiares: "Com a família foi complicado. Não aceitavam, eles achavam que era loucura nossa. Eu já tava meio estressada, nervosa com tudo o que tava acontecendo. Eu principalmente falava o que não devia às vezes" (M3). A forma que esta mãe e seu marido encontraram de lidar com a situação foi tentar ignorar as colocações dos familiares e seguir as orientações da equipe médica: "Ou tu escutava o que os médicos estavam falando e mostrando pra ti ou tu ia pela opinião deles. E a família parecia que queria fugir daquela realidade" (M3). Outra questão marcante foi o fato de ter havido uma morte acidental nesta família e os parentes, segundo o relato materno, terem se negado a doar os órgãos. $\mathrm{O}$ órgão não seria de qualquer forma doado para a filha, mas o ato foi sentido como uma falta de empatia:

Os parentes falaram que jamais, jamais iam deixar tirar nada dele [acidentado], nada! Mas a gente não briga por causa disso, não fica difamando uma à outra, porque o corpo é dela, ela que faz o que ela quer. Só que a gente fica se perguntando lá no fundo se... se ela não vê que por causa do órgão de outra pessoa que a $\mathrm{C}$ ganhou a vida de novo. (M3).

Como pode ser visto nos relatos, a situação de doença e transplante levou, de uma forma geral, a uma maior proximidade da família extensiva, devido à necessidade que tiveram de se unir para enfrentar os desafios impostos pela situação de doença e transplante. Neste sentido, o diálogo com a família extensiva parece ter se tornado mais freqüente. $\mathrm{O}$ apoio emocional dado aos genitores, $\mathrm{o}$ cuidado das crianças enfermas e dos filhos saudáveis, foram destacados como fatores de relevância pelas mães.

\section{Discussão Geral}

Os resultados mostraram que a doença crônica e o transplante tiveram um forte impacto na dinâmica familiar, que se estendeu ao longo dos anos, independente do tempo transcorrido desde o transplante. Na relação com o filho transplantado apareceram comportamentos superprotetores e permissivos, dificuldade de manejo e imposição de limites, associado a uma tentativa de protegê-los ou compensá-los pelo sofrimento vivido. Outra questão que surgiu e motivou alguns dos casais a não serem firmes com seus filhos transplantados foi o receio de que qualquer contrariedade pudesse prejudicar o estado de saúde dos mesmos. Assim, a dificuldade encontrada por mães e pais em educar seus filhos enfermos, parece estar associada ao medo da morte, ao receio de causar mais sofrimento e ao desejo de aproveitar sua convivência ao máximo, sem ter de submeter os filhos a outras frustrações e momentos estressantes, como os implicados na educação. Com isto, algumas crianças acabaram tornando-se indisciplinadas, conseguindo controlar os pais através de manipulações, apoiando a literatura (Anton, 2006; Castro \& Moreno-Jimenéz, 2005; Kärrfelt et al., 2000; Masi \& Brovedani, 1999; Piccinini et al., 2003).

Poucos casais parecem ter conseguido adotar uma postura mais firme com os seus filhos e procuraram manter o padrão de educação que imaginavam que teriam caso não tivessem passado pela situação de doença e transplante. Os casais que procuraram ser mais firmes parecem ter tido que se esforçar para não ceder ao impulso de superproteger os filhos, já que tinham uma percepção que este tipo de comportamento poderia tornar as crianças mais frágeis e, conseqüentemente, menos capazes de lidarem com as exigências de cuidados impostos pela doença e o transplante.

A utilização de mais práticas educativas indutivas do que coercitivas também ficou evidenciada nos relatos maternos, o que poderia ser considerado um aspecto positivo na vida dessas famílias. No entanto, a utilização de barganha também foi constatada. O cerceamento da criança apareceu, já que, devido ao excesso de preocupação, estas mães tendiam, muitas vezes, a não permitir que os filhos tivessem atividades características da idade. Apesar de, em algumas situações, as mães terem associado à superproteção com a doença, de uma forma geral tenderam a negar tal relação, justificando-a de outras formas. Assim, a presença de doença crônica e transplante constitui-se como um organizador de respostas parentais às crianças, com conseqüências para as interações (Castro \& Moreno-Jiménez, 2005; Piccinini et al., 2003), sendo que a interação precoce da díade pode ser caracterizada por sentimentos de ansiedade e medo da morte iminente.

Além disso, pôde-se verificar que uma mudança extrema na vida dessas famílias ocorreu em virtude da necessidade de adaptação à situação de doença crônica e transplante. Os resultados apontaram que esta situação representou um desafio na vida das famílias, já que trouxe uma série de dificuldades que envolveram restrições financeiras, afastamento físico do casal e dos filhos, falta de tempo e energia para investir na relação conjugal, com ocorrência de conflitos familiares. Estes achados corroboram o exposto pela literatura que indica ser comum nestas situações, o relacionamento do casal ficar em segundo plano, e também o surgimento de problemas maritais e fraternais (Fine et al., 2004), assim como perda de rendimentos e ameaça ao bem-estar financeiro (Engle, 2001).

Em relação aos irmãos das crianças transplantadas, os resultados do estudo apontaram que estes também tenderam a ficar em segundo plano, em função da necessidade de cuidados que a doença impunha, corroborando a literatura (Fine et al., 2004; Lewis \& Wolkmar, 1993). Muitas vezes acabaram ficando sob os cuidados de parentes e afastados dos pais. Apesar dos sintomas que 
alguns destes irmãos apresentaram - inclusive com a reprovação escolar em um dos casos - estes parecem não terem sido suficientemente valorizados pelas mães, que centravam seus comentários no fato dos filhos terem compreendido e aceitado a situação. Isto talvez tenha ocorrido como uma forma de se proteger de mais um sofrimento que representaria admitir o impacto da doença nos outros filhos e as consequiências do ponto de vista psíquico que podem ter acarretado, já que realmente estas famílias não tinham outra alternativa a não ser investir na tentativa de salvar a vida de seus filhos.

Outro aspecto que se salientou foi a grande preocupação destas crianças com a saúde dos irmãos transplantados. Estes fatores foram muito valorizados pelas mães, que pareciam interpretar tais atitudes como indicadores de maturidade e amor pelo irmão enfermo. No entanto, isto também pode estar denunciando uma pseudo-adaptação dos filhos sadios ao padrão de funcionamento familiar e uma tentativa de agradar aos pais, para, também serem valorizados. A partir de uma perspectiva psicanalítica (Freud, 1936/1968) este fato também poderia ser entendido como uma formação reativa, ou seja, uma necessidade dos filhos sadios de cuidar, proteger e reparar o ataque que em suas fantasias fizeram aos irmãos enfermos, já que sentimentos de inveja, rivalidade e raiva parecem ter sido despertados pelo fato de terem se sentido relegados em função da doença. Além disso, o desamparo e o intenso sentimento de perda ficaram evidentes nos relatos maternos, tendo sido muito bem descrito na verbalização de uma das mães que conseguiu dar-se conta de que, na verdade, a perda para os filhos sadios foi dupla, já que, além de terem perdido o convívio com a mãe, perderam também a irmã sadia que aguardaram nove meses para nascer.

Com relação à família extensiva, pôde-se perceber que as relações familiares acabaram permeadas pela história de doença e transplante. Tanto as famílias cujos filhos haviam transplantado há um ou dois anos, quanto aquelas cujo transplante ocorreu há cinco ou seis anos atrás, ainda sofriam com grande intensidade o impacto desta vivência. O que foi mudando com o passar do tempo foi o maior grau de convivência dentro da família, principalmente da mãe com o marido e com os filhos sadios, já que, no auge da doença, as mães tiveram que ficar mais afastadas devido às internações hospitalares.

Neste contexto de extrema gravidade e complexidade, ficou evidente a importância da união e do diálogo entre os envolvidos como fator de manutenção da relação do casal e da vida familiar. Os resultados do presente estudo revelaram uma maior proximidade emocional da família como um todo. Neste sentido, o diálogo entre o casal, do casal com a criança doente e com a família extensiva pareceu ter se tornado mais frequiente. De forma geral, os casais e os adultos da família, dividiam as dificuldades e sofrimentos enfrentados, enquanto, com a criança, procuravam falar dos pontos positivos e passar confiança e esperança de cura.
No entanto, o assunto do doador mostrou-se um tema difícil, abordado por poucas mães, sendo que as que o fizeram mostraram ansiedade diante do tema. Isto ocorreu, provavelmente, pelo fato do tema mobilizar sentimentos persecutórios e culpa, assim como sentimento de dívida com o doador (Gritti et al., 2001; Masi \& Brovedani, 1999; Wise, 2002). Além da dificuldade de falar sobre o doador, o assunto do transplante, segundo Gritti et al. (2001), também tende a ficar freqüentemente ausente da comunicação entre a criança e os pais. No presente estudo apenas alguns genitores tiveram esta postura por acreditar que os filhos não entenderiam tais informações. Outros, diferentemente do que aponta a literatura, procuravam conversar com as crianças e explicar tudo que estava acontecendo, na tentativa de auxiliar na adaptação à situação vivida. Desta forma, evitaram que o tema do transplante se tornasse um tabu, o que, segundo alguns autores (Anton, 2006; Gritti et al., 2001), teria conseqüências negativas, ao tornar o processo silencioso e solitário para a criança, dificultando a elaboração psíquica da experiência de doença crônica e transplante. Cabe ressaltar que esta diferença na atitude dos pais desse estudo, talvez possa ter se dado em função da influência da equipe de psicologia que têm destacado, nos atendimentos psicológicos que realizam sistematicamente, a importância da comunicação com estas famílias e das famílias entre si e com a criança.

Como limitações do presente estudo pode-se apontar o fato de não se ter incluído observações das relações familiares, assim como não ter entrevistado os pais das crianças transplantadas e demais familiares. Desta forma, obteve-se um panorama exclusivamente materno. Outro aspecto que deve ser destacado é o fato deste ter sido um estudo retrospectivo. Em virtude disso, as lembranças maternas podem ter sofrido modificações com o passar dos anos, não refletindo com exatidão a vivência daquele momento. No entanto, relatos similares foram obtidos tanto das mães cujos filhos transplantaram entre um e dois anos atrás, quanto daquelas cujos filhos transplantaram há cinco ou seis anos. Cabe lembrar ainda que o estudo se refere apenas a transplante hepático infantil. É provável que os resultados sejam válidos para outros tipos de transplantes de órgãos infantis, mas isso merece novas investigações.

\section{Considerações Finais}

Como pôde ser visto, a situação de doença crônica e de transplante tem um importante impacto nas relações familiares. Tendo em vista as várias consequiências do ponto de vista emocional reveladas pelas mães no presente estudo, a indicação de acompanhamento multiprofissional se faz extremamente necessária no contexto da doença crônica, especialmente quanto envolve transplante. Do ponto de vista psicológico cabe destacar a relevância de intervenções precoces e de um acompanhamento psicoterapêutico sistemático à criança e a 
família que vise a diminuir o sofrimento psíquico dos envolvidos. Atenção especial deve ser dada às relações familiares, especialmente à relação mãe-pai-criança, ao manejo parental do filho enfermo. A relação com os filhos sadios também merece atenção especial, tendo em vista o impacto que a situação de afastamento dos pais pode causar nos irmãos. Neste sentido, o atendimento psicológico pode auxiliar estas crianças e suas famílias a lidarem com a situação de doença e transplante da forma mais adaptativa possível, ao propiciar que as inevitáveis ansiedades parentais e infantis venham à tona num setting terapêutico no qual podem ser trabalhadas tecnicamente, a fim de elaborar eventuais conflitos. Este processo de elaboração pode levar a diminuição do intenso investimento na doença e suas limitações e a um maior investimento na vida e nas relações familiares.

\section{Referências}

Adebäck, P., Nemeth, A., \& Fischler, B. (2003). Cognitive and emotional outcome after pediatric liver transplantation. Pediatric Transplantation, 7, 385-389.

Anton, M. C. (2006). Quando a criança adoece. In I. L. C. Anton (Ed.), Cegonha à vista: E agora, o que vai ser de mim? (pp. 165-174). Porto Alegre, RS: Est.

Anton, M. C., \& Piccinini, C. A. (2006a). Entrevista sobre a história da doença e do transplante hepático infantil. Manuscrito não-publicado, Instituto de Psicologia, Universidade Federal do Rio Grande do Sul, Porto Alegre, RS.

Anton, M. C., \& Piccinini, C. A. (2006b). Entrevista sobre a experiência da maternidade e o relacionamento familiar no contexto do transplante hepático infantil. Manuscrito nãopublicado, Instituto de Psicologia, Universidade Federal do Rio Grande do Sul, Porto Alegre, RS.

Anton, M. C., \& Piccinini, C. A. (2006c). Entrevista sobre o desenvolvimento emocional da criança no contexto do transplante hepático infantil. Manuscrito não-publicado, Instituto de Psicologia, Universidade Federal do Rio Grande do Sul, Porto Alegre, RS.

Anton, M. C., \& Piccinini, C. A. (2010). Desenvolvimento emocional em crianças submetidas a transplante hepático. Manuscrito submetido à publicação.

Anton, M. C., \& Piccinini, C. A. (2010). A experiência da maternidade no contexto de transplante hepático infantil. Manuscrito submetido à publicação.

Anton, M. C., \& Piccinini, C. A. (2010). Aspectos psicossociais associados a diferentes fases do processo de transplante hepático pediátrico, Psicologia: teoria e pesquisa (in press).

Castro, E. K., \& Moreno-Jiménez, B. (2005). Funcionamiento familiar en situación de trasplante de órganos pediátrico. Revista Interamericana de Psicología, 39(3), 383-388.

Castro, E. K., \& Piccinini, C. A. (2004). A experiência da maternidade de mães de crianças com e sem doença crônica no segundo ano de vida. Estudos Psicológicos, 9(1), 89-99.

Engle, D. (2001). Psychosocial aspects of the organ transplant experience: What has been establisched and what we need for the future. Journal of Clinical Psychology, 57(4), 521-549.

Falkenstein, K. (2004). Proactive psychosocial managemente of children and their families with chronic liver diease awaiting transplant. Pediatric Transplantation, 8, 205-207.

Ferreira, C. T., Vieira, S. M. G., \& Silveira, T. R. (2000). Transplante hepático. Jornal de Pediatria, 76(2), 198-208.
Fine, R. N., Alonso, E. M., Fischel, J. E., Bucuvalas, J. C., Enos, R. A., \& Gore-Langton, R. E. (2004). Pediatric transplantation of the kidney, liver and heart: Summary report. Pediatric Transplantation, 8, 75-86.

Freud, A. (1952). The role of bodily illness in the mental life of children. In The psychoanalytic study of the child (Vol. II, pp. 69-81). New York: International University Press.

Freud, A. (1968). O ego e os mecanismos de defesa. Rio de Janeiro, RJ: Biblioteca Universal Popular. (Original publicado em 1936)

Gritti, A., Di Sarno, A. M., Comito, M., De Vincenzo, A., De Paola, P., \& Vajro, P. (2001). Psychological impact of liver transplantation on children's inner worlds. Pediatric Transplantation, 5(1), 37-51.

Kärrfelt, H. M. E., Berg, U. B., \& Lindblad, F. I. E. (2000). Renal transplantation in children: Psychological and donation-related aspects from the parental perspective. Pediatric Transplantation, 4, 305-312.

Kärrfelt, H., Lindblad, F. I. E., Crafoord, J., \& Berg, U. B. (2003). Renal transplantation: Long-term adaptation and the children's own reflections. Pediatric Transplantation, 7, 69-75.

Laville, C., \& Dionne, J. (1999). A construção do saber: Manual de Metodologia da Pesquisa em Ciências Humanas (L. M. Siman, Trad.) Porto Alegre, RS: Artes Médicas.

Lewis, M., \& Wolkmar, F. (1993). Reações psicológicas à doença e à hospitalização (G. Giacomed, Trad.). In M. Lewis \& F. Wolkmar (Eds.), Aspectos clínicos do desenvolvimento na infância e adolescência (pp. 101-113). Porto Alegre, RS: Artes Médicas.

Masi, G., \& Brovedani, P. (1999). Adolescents with congential heart diesease: Psychopathological implications. Adolescence, 34(133), 185-191.

Piccinini, C. A., Castro, E. K., Alvarenga, P., Vargas, S., \& Oliveira, V. Z. (2003). A doença crônica na infância e as práticas educativas maternas. Estudos em Psicologia (Natal), 8(1), 75-83.

Sokal, E. M. (1995). Quality of life after orthotopic liver transplantation in children: An overview of physical, psychological and social outcome. European Journal of Pediatrics, 154, 171-175.

Stake, R. E. (1994). Case studies. In N. Denzin \& Y. Lincoln (Eds.), Handbook of qualitative research (pp. 236-247). London: Sage.

Tarbell, S. E., \& Kosmach, B. (1998). Parental psychosocial outcomes in pediatric liver and/or intestinal transplantation: Pretransplantation and the early postoperative period. Liver Transplantation and Surgery, 4(5), 378-387.

Törnqvist, J., Van Broeck, N., Finkenauer, C., Rosati, R., Schwering, K. L, Hayez, J. Y., et al. (1999). Long-term psychosocial adjustment following pediatric liver transplantation. Pediatric Transplantation, 3(2), 115-130.

Wise, B. V. (2002). In their own words: The lived experience of pediatric liver transplantation. Qualitative Health Research, 12(1), 74-90. 